\title{
Challenges in mathematics teacher education
}

\author{
Olive Chapman
}

Published online: 27 July 2012

(C) Springer Science+Business Media B.V. 2012

Mathematics teacher education is highlighted by its complexities and challenges, particularly when the goal is to prepare prospective teachers and to help practicing teachers to teach in ways that they did not experience as learners of mathematics. Thus, while the four articles in this issue of the Journal of Mathematics Teacher Education (JMTE) offer different views/aspects of mathematics teacher education, it is the implied challenges that caught my attention as a common theme. Each article prompted me to think of a different challenge that I briefly address.

\section{Implementing a new curriculum}

Implementing reform-oriented mathematics curricula has been the focus (directly or indirectly) of many studies on mathematics teachers. A significant influence on this is the perspective that teachers are central to how the curriculum gets interpreted and lived in the classroom. Within this perspective lie the challenges for teacher education. For example: What knowledge should teachers hold to teach a reform-oriented curriculum? What approaches will effectively facilitate development of this knowledge and application of it in the classroom? What is the nature of the teachers' thinking (e.g., beliefs, attitude) or identity in relation to the curriculum and the relationship to their learning and teaching? While all of these factors are important and require ongoing attention, I focus on teachers' beliefs and attitudes to offer an example of them based on a study with which I was involved.

Mathematics teachers' beliefs and attitudes toward a new curriculum are likely to be directly related to their beliefs and attitudes toward their learning and teaching of it. For example, if the teachers' beliefs are not in harmony with those framing the curriculum, this can affect the level of their participation and success in activities to help them to understand and implement the curriculum as intended. In general, teachers' beliefs and attitudes can play either a facilitating or an inhibiting role in their learning of the new curriculum.

O. Chapman $(\bowtie)$

University of Calgary, Calgary, AB, Canada

e-mail: chapman@ucalgary.ca 
For example, if the teachers hold beliefs compatible with the new curriculum, learning and implementing it are more likely to occur regardless of the approach to help them to accomplish this. However, if they hold conflicting beliefs or perceive barriers in implementing and enacting the curriculum, helping them to learn it will likely pose greater challenges for both them and the teacher educators and make application of it difficult. Similarly, if they have positive attitudes about the curriculum, they are likely to display positive attitude to learn and implement it, while negative attitudes will likely make it more difficult to engage them in learning and implementing it. In general, then, teachers' compatible beliefs and positive attitudes for the new curriculum could facilitate more positive engagement in learning it. This suggests that questions such as the following are important to address in teacher education: What is the nature of teachers' beliefs and attitudes in relation to implementing a new mathematics curriculum and the implications for professional development? What affects the teachers' attitudes when faced with a new curriculum in mathematics education? What are the teachers' attitudes toward the curriculum, in general, and in relation to specific groups of students, in particular?

Based on a study to investigate mathematics teachers' beliefs and attitudes in implementing a new project-based high school (grades 10-12) mathematics curriculum (Chapman and Wood 2004), I briefly highlight the nature of these beliefs. This curriculum emphasizes "the application and relevance of mathematics in daily life." It is intended for students who are not likely to attend university or pursue an academic area at university that requires mathematics. The textbooks produced for it consist predominantly of projects.

The participants were experienced teachers at the beginning of the second year of implementation of the curriculum. Three of the themes emerging from the data involved their common beliefs about the nature of the projects, small-group learning, and support for implementation. The teachers' beliefs about the nature of the projects focused on the utility of mathematics and relevance to students. They viewed mathematics as meaningful to these students only when it is related to applications that were relevant to them. Thus, they believed that the curriculum content was more relevant and meaningful to students because of the focus on real-world situations. This supported their positive attitude to implementing the curriculum. However, their beliefs allowed them to place more emphasis on using the projects to motivate students but limited the mathematical scope and depth in which they implemented the curriculum.

The teachers believed that teaching and learning through projects was the way to teach mathematics and would result in a more interesting way of learning for the students, but they did not use this approach in their prior teaching, in particular, the use of investigations and groups. The projects were set up as small-group investigations, which challenged the teachers' beliefs about using groups in the mathematics classroom. They considered groups as unnecessary in learning mathematics. Thus, the focus on group work was not considered an asset. For example, one teacher explained, "I don't see the point of why we have to work in groups. The projects could have been fine to do individually." Another teacher thought that this was changing a unique part of mathematics instruction.

Mathematics classrooms had something that was a little different. In science they group up, in English they group up, in social [studies] they group up, so we [mathematics] did not group up, so I do not mind the grouping up, but it had strong points to not group up.

Thus, their implementation of groups was very controlled. In spite of this, they recognized the importance for students' autonomy. For example: 
Anytime you can give the student the opportunity to learn first, the better it is for the student. I think that the kind of an inverse relationship, the less the teacher does, the better the teaching is. That is what this new curriculum is saying; it's great!

Finally, the teachers believed that the best form of support for their implementation of the curriculum was from within their schools. While they valued the workshops they attended in their school system, they considered the internal support to be more important. They also believed that getting time to read the text book, to plan the lessons, and to ask questions was more important "to figure it out" than the workshops by the school system. They were unaware of how this limited the implementation to what they could understand by themselves, which may not represent the curriculum itself.

This study provides evidence of how teachers' beliefs can influence if and how a new curriculum gets implemented and an example of what teachers could believe is important to aid the implementation process. It reminds us of the importance to attend to beliefs in mathematics teacher education, in particular, dealing with the challenge of surfacing tacit beliefs and the complex relationship between beliefs and actions in the implementation of a new curriculum.

\section{Making connections to real-world contexts}

Mathematics education documents in the form of a curriculum or standards are now explicitly emphasizing connections as one of the important processes in learning and doing mathematics. For example, the National Council of Teachers of Mathematics (2008) standard for the process of connections states that instructional programs should enable students to "Recognize and apply mathematics in contexts outside of mathematics" (p. 64). This includes making connections to the "real world," that is, the out-of-classroom world. Teachers, then, are now expected to provide real-world situations and contexts for students to make sense of mathematical ideas and to provide opportunities for them to recognize and celebrate the mathematical connections to their lives. This means that teachers themselves need to be able to recognize and understand such connections, which will likely require that they consider mathematics and their teaching in a new way. As Nicol (2002) found, prospective teachers were not able to unpack the mathematics and the mathematical demands of work in various contexts and when they did focus on the mathematics used in a context, they recontexualized it or decontextualized it in ways that lost the authenticity of the context and the richness of the mathematics.

The challenge for teacher education includes addressing questions such as: What do teachers recognize as mathematics in real-world situations? How do they (or are they able to) make connections between classroom practices and real-world uses of mathematics? What kinds of real-world connections make the most sense for teachers to learn about and use in their teaching? What approach will help teachers to learn to work with real-world contexts in a way that does not trivialize or dismiss the important mathematics embodied in them? In relation to this last question, I have reviewed manuscripts to JMTE that reported on studies, aimed at using tasks with real-world contexts to facilitate prospective teachers' learning, in which the mathematics got lost or was trivialized while the context was emphasized or vice versa. These manuscripts indicated how teacher educators/researchers could treat this situation in a non-problematic way that overlooks the challenge in addressing both the mathematics and the real-world aspects of the task with meaningful depth. They also suggested that engaging the teachers in real-world contextual 
mathematical tasks by itself does not deal with this challenge and more appropriate approaches must be employed.

\section{Sustainable change or learning process}

Many studies in JMTE report on teacher education or professional development programs that are successful in helping teachers to change during the programs but sustainability of the change and learning process is often not clear or addressed. Such sustainability is important to produce large-scale shifts toward reform-oriented mathematics pedagogy. Professional development programs, then, should aim not only at creating change during the programs but more importantly to help teachers to be able to sustain it. However, here is where the challenge for teacher education presents itself, that is, how to work with teachers to develop sustainable change and learning toward ongoing improvement in their teaching of mathematics.

Traditional, show-and-tell approaches to mathematics teacher professional development, instead of sustaining change, lead to a dependency culture in which the teachers expect that future teaching ideas or strategies, following the initial learning opportunity, should be given to them in a ready-made form for implementation in the classroom. In contrast, recent focus on programs involving practice-based professional learning communities in which teachers are actively engaged in their own learning seems to be more promising to accomplish some level of sustainability and ongoing learning. These programs need to recognize and emerge from the teachers' thinking and experiences and provide them with extended opportunities to construct useful knowledge and ways of transforming their teaching for themselves.

In spite of such teacher-oriented programs, sustainability can be a challenge for teachers because of various factors that restrict ongoing change and learning after the initial learning experience. Teachers face challenging circumstances once on their own that could negatively impact sustainability of ongoing change and learning, in particular, when the change and learning involve different ways of being and knowing from those with which they are more comfortable based on past experiences. These challenges could result from external and/or internal factors. For example, if all of the mathematics teachers in a school are not on the same path of change, this could negatively impact ongoing change for the individuals trying to do so. In addition, if the change is not happening at all grade levels in the school, teachers who are trying to change to reform-oriented instructional strategies will encounter challenges from students who are more comfortable with their previous teacher-directed classrooms. An example of internal factors that could negatively impact sustainability is the teachers' tacit beliefs that may need to change but are difficult to access during the professional development, which then can restrict the teachers' ways of thinking and actions in the classroom. Sustainability is thus a complex endeavor that requires ongoing attention in the mathematics teacher education research community.

\section{Implementing technology}

In addressing the role of technology in the teaching and learning of mathematics, the NCTM (2008) states: "Technology is an essential tool for learning mathematics in the twenty-first century, and all schools must ensure that all their students have access to technology" ("Implementing a new curriculum"). However, having access is only one of 
the necessary ingredients to support integration of technology in the mathematics classroom. Implementation of such recommendations is dependent on the teacher and the knowledge they hold or ought to hold to use technology to enhance mathematical understanding for themselves and their students. Given that teachers educated in traditional mathematics classrooms have not learned mathematics with these technologies, they are likely to have limited knowledge of both the technologies for use in mathematics and how to use them. So the challenge for teacher education is to identify what knowledge is needed and how to prepare prospective and practicing mathematics teachers to use technology in a way that leads to the development of technological pedagogical content knowledge (TPCK) for teaching mathematics.

In order to meet this challenge, questions such as the following should be addressed: What do teachers need to know and be able to do and how do they need to develop this knowledge for teaching mathematics with technology? What are the appropriate conditions or frameworks for the development of TPCK for prospective and practicing teachers? In addition, similar challenges as with the implementation of a new curriculum apply here in terms of the teachers' attitudes and beliefs about teaching mathematics with technology. There is also the issue of technology anxiety. For example, how do these affective factors support and/or restrict or create barriers to the teachers' learning and use of technology? How are they exposed in order to address them? Understanding such questions could lead to meaningful ways of addressing some of the challenges to help teachers to acquire the knowledge and experiences needed to incorporate technology in their teaching of mathematics.

\section{Articles in this issue of JMTE}

As previously noted, although not an explicit goal of each, the four articles in this issue of JMTE collectively make a contribution to our understanding of aspects of the above four challenges. For example, Edd Taylor addresses connections to students' out-of-school experiences and provides insights of challenges with teachers' learning and a possible way of addressing them. Laura Van Zoest, Shari Stockero, and Cynthia Taylor's article provides insights regarding sustainability of learning through the use of sociomathematical and professional norms. João Pedro de Ponte addresses a professional development approach to the implementation of a new mathematics curriculum. Mustafa Dogan deals with prospective teachers views of technology in their learning and teaching. Some highlights of each article are provided next.

Edd Taylor's research report describes a year-long professional development program designed to support teachers' use of students' everyday practices to improve classroom mathematics. The participants were 14 female elementary school teachers. The professional development required them to discover the mathematics in which their students were engaged outside of school, match those practices to classroom mathematics, design lessons that made use of the connections they identified, and evaluate the success of the lessons they created. The outcome of this approach was that while teachers found creative ways to use the context that children engaged in outside of school, many had greater difficulty thinking about the mathematics that the children used in that context. In order to address this resulting challenge of how to better support thinking about the mathematics contained in out-of-school practices in ways that would result in greater success in building on students' informal knowledge, he developed two activity probes to help the teachers think about the type of mathematics children used in their everyday practices and the 
mathematics they included in their lessons. With this guidance, the ways that teachers' lessons drew on their students' knowledge acquired through their involvement in activities outside of school improved. While early lessons seemed to focus only on context, in the post-probes lessons, the teachers began to look more deeply at how the mathematics in the out-of-school activity was similar to the mathematics in the school context. Thus, the focused probes were helpful in highlighting the importance of context paired with the mathematics contained in that particular context in subsequent lessons.

The study also included an analysis of the possible influence of the professional development facilitators and the assigned readings on developing a focus on a particular approach to designing lessons that draws on informal mathematical knowledge. Thus, the overarching outcome of the study was the creation of The Multi-Approach Engagement Framework, which describes ways particular types of activities are similar to the types of children out-of-school activities and how the mathematics within these activities are embedded within practice. Taylor describes his work as an early step into understanding the benefits and challenges of utilizing everyday mathematical knowledge for the specific purpose of supporting classroom mathematics. He suggests that further research may need to examine links between particular approaches to linking in- and out-of-school learning and particular goals of the professional development.

Laura Van Zoest, Shari Stockero, and Cynthia Taylor's research report describes a study that investigated the extent to which three sociomathematical and four professional norms intentionally fostered in an early mathematics pedagogy course re-emerged in a similar context. The participants were 11 prospective secondary school mathematics teachers in the final mathematics pedagogy course of the same teacher education program and 16 selfselected beginning secondary school mathematics teachers who were graduates of the same program with fewer than 4 years of teaching experience. The authors viewed the seven norms as supporting teachers to improve their own mathematical understanding, learn to view and analyze classroom practice in productive ways, think about developing norms in mathematics classrooms with students, and develop professional dispositions that support continued learning from practice. As part of the study, the two groups of participants engaged in parallel activities that were similar to those they had participated in during the initial pedagogy course, using video materials. Both groups used the same mathematics problem, analyzed the same video, and completed the same written work. In particular, the participants focused on analyzing student thinking and considering the implications of the teacher's actions for supporting student thinking in ways that are not commonly seen in teacher professional development.

The researchers examined the data to determine whether the seven target behaviors were normative for the prospective and beginning teachers. All seven norms were found to be durable over time, with the sociomathematical norm of providing a mathematical argument being the most widely and consistently exhibited among the participants. Five of the norms were consistently durable over time with both groups of participants, and their engagement with two of the norms was positively affected by additional classroom experience. The results point to the long-term benefits of developing productive norms early in a teacher education program. The authors conclude that this study supports the idea that intentionally developing productive sociomathematical and professional norms early in a teacher education program has the potential to contribute to teachers' continued learning from practice, supporting them in ways that could lead to self-sustaining generative change. Thus, this study provides evidence that an investment in developing productive norms at one level can support future learning at another level. 
João Pedro de Ponte's article, in the mathematics teacher education around the world category, provides insights about a national professional development program (the "extended workshop") that was used in the preparatory stages of the introduction of a new mathematics curriculum in Portugal. This curriculum indicates two main purposes for mathematics education: to promote mathematics learning and the ability to use mathematics in different contexts and to promote positive attitudes and appreciation of mathematics. It also favors an exploratory approach and emphasizes three mathematical processes (i.e., problem solving, mathematical reasoning and mathematical communication) that must be continuously addressed while working on the content themes.

The extended workshop was based on five major ideas-orientation toward teachers' professional practice, focus on students' learning, collaboration, teachers researching their own practice, and change of teachers' professional culture. Evaluation of the workshops indicated that some of the teachers who already had a high alignment with the new orientation of the curriculum showed a clear support for it, some showed interest in learning about it, and others showed reservations. Teachers who were less attuned to the new curriculum orientations had more difficulty in making sense of the rationale behind the exploratory tasks. But many others showed a high interest in trying out the new curriculum perspectives in their classrooms. The emphasis on practice, the work with materials directly related to the classroom activity and the collaborative setting were well accepted by most participants. But the research aspect was considered to be challenging and resulted in some concern for many. The most complex phase of the workshops was the final discussion that was a new experience for many of the teachers.

Mustafa Dogan also contributes an article to the mathematics education around the world category. He explored prospective Turkish primary mathematics teachers' views about the use of computers in mathematics education. The adjusted sample comprised of 129 fourth year prospective primary mathematics teachers from two different universities in Turkey. The specific aim of the study was to investigate their experience with computers up to the end of their teacher education program in order to understand the situation in Turkey from their perspective. Data consisting of participants' written responses to a survey question were qualitatively analyzed and categorized according to the Technological Pedagogical Content Knowledge framework.

Results showed that the participants' comments typically emphasized the importance of using computers to improve understanding of different mathematics topics. However, a reasonably large number of respondents expressed negative feelings about computers and computer-based mathematics education. They also indicated that they were neither confident nor sure about their technical skills and personal abilities for using computers in class to teach mathematics. They enjoyed working with computers even though they were only able to perform relatively minor calculations with them. They stated that improved use of the computer could help them to learn how to use it to teach mathematics more effectively. Dogan concluded that providing more purposeful activities may increase Turkish prospective mathematics teachers' views, performance and confidence about technology usage in mathematics education.

To conclude, these four articles provide a broader lens to view mathematics teacher education in international contexts than that of challenges. However, in highlighting some of the important challenges that contribute to the complexity of mathematics teacher education, it is hoped that they encourage further research of them to deepen our understanding of how to deal with them effectively. 


\section{References}

Chapman, O., \& Wood, L. (2004). Teachers' beliefs influencing the implementing of a project-based high school mathematics curriculum. In D. McDougall \& A. Ross (Eds.) Proceedings of the twenty-sixth annual meeting of the North American chapter of the psychology of mathematics education vol. 2. Toronto, ON: University of Toronto, p. 954.

National Council of Teachers of Mathematics (2008, March). The role of technology in the teaching and learning of mathematics. Retrieved May 31, 2012, from http://www.nctm.org/about/content.aspx? $\mathrm{id}=14233$.

Nicol, C. (2002). Where's the math? Prospective teachers visit the workplace. Educational Studies in Mathematics, 50(3), 289-309. 